\title{
UMA BREVE ANÁLISE SOBRE A RELAÇÃO CONSCIÊNCIA- MUNDO: O EGO COMO FUNDAMENTO ABSOLUTO
}

\author{
Estanislau Fausto ${ }^{1}$
}

RESUMO: O problema do ego é parte fundamental da obra de Husserl. Essa estrutura tem, para o autor, uma dimensão absoluta, sem a qual não há possibilidade de conhecimento. Este trabalho tenta apresentar de forma simples e direta a formulação husserliana do ego e como o autor percebeu a relação consciência-mundo.

PALAVRAS-CHAVE: Fenomenologia, Husserl, Descartes, Ego.

ABSTRACT: The problem of ego is a fundamental part of the work of Husserl. The ego have for the author an absolute dimension without which there is no possibility of knowledge. This article presents of a simple way how is given to formulation of Husserl's ego and how the author perceives the consciousness-world relation.

KEYWORDS: Phenomenology, Husserl, Descartes, Ego. 
UMA BREVE ANÁLISE SOBRE A RELAÇÃO CONSCIÊNCIA-MUNDO:...

Reestruturar a filosofia como uma ciência de rigor - em resumo, eis a grande proposta filosófica encontrada na obra de Husserl. Certamente não é algo novo na história da filosofia e Husserl reconheceu isso, dando grande parte do valor da empreitada a Descartes. Pode-se dizer que a questão fenomenológica-transcendental é uma decorrência histórica e filosófica do método cartesiano, assim como do seu problema. Em linhas gerais, referir-se a Descartes como o pai da fenomenologia indica que o método husserliano teve a mesma preocupação cartesiana, a saber, assegurar uma estrutura indubitável como fundamento da ciência.

Como se sabe, Descartes sustentou uma proposta de reconstrução das bases do conhecimento, demonstrando como a realidade é dubitável. Colocando tudo o que se podia pôr em dúvida, o filósofo pretendeu elevar $\mathrm{o}$ conhecimento de verdade em verdade e estagnar a própria dúvida em um fundamento que se funda a si. $\mathrm{O}$ "penso, logo existo", em sua possibilidade de verificação, foi tido por Descartes como o firmamento para erigir um novo sistema de crenças. Da mesma forma, a temática filosófica de Husserl perpassou uma nova tentativa de fundamentar de forma sistemática e unitária a filosofia. Para que isso fosse possível, assim como ocorreu na obra de Descartes, o conceito de eu como estrutura-em-si foi fulcral na análise fenomenológica. 
Não deixa de ser curioso notar que Husserl elevou Descartes ao papel de: "o maior pensador francês" (HUSSERL, 2010, p. 51) e, por essa grande influência filosófica, seria possível assumir a fenomenologia como um quase neocartesianismo. Todavia, como enfaticamente indicou G. Lebrun, o problema é justamente o "quase”. A admiração de Husserl pela filosofia cartesiana ocorreu devido ao alumbramento filosófico da inauguração da subjetividade. Além, é claro, da tentativa de Cartesius de realizar uma Mathesis Universalis. Entretanto, afirmou Lebrun:

Quando, porém, busca-se determinar em que consiste o mérito de Descartes aos olhos de Husserl, percebe-se, com algum espanto que esse mérito, tecnicamente é bem exíguo - e que ele se reduz a uma inspiração genial que o filósofo logo pós a perder. (LEBRUN, 2004, p.253).

De fato, para Husserl, Descartes avançou por demais rapidamente na tentativa de demonstrar a possibilidade da validade do conhecimento do mundo. Perdendo a grande vantagem da fundamentação da verdade indubitável do eu, que é, justamente, a inexistência da distinção entre ser e aparecer. Quando um objeto é percebido, pode-se duvidar da sua existência, pode-se supor que aquilo é uma mera 
UMA BREVE ANÁLISE SOBRE A RELAÇÃO CONSCIÊNCIA-MUNDO:...

representação de seu conteúdo, pode-se acreditar que o que se tem é um simples aparecer, mas não uma estruturação objetiva do ser, por fim, pode-se atribuir um gênio maligno como emissário das percepções difusas do objeto à consciência. Todavia, o mesmo não ocorre com o eu - afinal o eu é, ele está posto em si como seu próprio fundamento, o seu aparecer na consciência é o seu ser.

Na obra de Descartes, a tentativa de superar esse problema foi firmada pela busca de uma causa inicial além do próprio eu, mais exatamente, em Deus. Demonstrando a existência de Deus, o filósofo poderia concluir que, primeiro, há um mundo objetivo passível de ser conhecido. Segundo, sendo Deus total perfeição, Ele não agiria como um gênio maligno enganando sua criação. Assim, a existência de Deus seria necessária para garantir os juízos verdadeiros sobre o mundo. Descartes chegou a afirmar na terceira meditação que "tenho de alguma forma em mim primeiro a noção de infinito do que do finito, ou seja, de Deus, do que de mim mesmo (DESCARTES, 2016, p.72).

O cogito cartesiano, com efeito, deslizou para o segundo lugar no plano ontológico. Como destacou Paul Ricoeur:

O Cogito seria realmente absoluto, em todos os aspectos, caso se pudesse mostrar que só há uma ordem, aquela na qual ele é efetivamente primeiro, e 
que a outra ordem, que o faz regredir para a segunda categoria, deriva da primeira. Ora, parece realmente que a Terceira Meditação inverte a ordem, colocando a certeza do Cogito em posição subordinada em relação à sua veracidade divina, que é primeiro segundo a "verdade da coisa". (RICOEUR, 2014, p. XXI)

A existência de um ser perfeito entrega de antemão a possibilidade de conhecimento do mundo externo. $\mathrm{O}$ próprio eu aparece como uma verdade estéril, deixando a escalada do edifício do conhecimento à deriva da necessidade de Deus. Husserl, todavia, não pretendeu seguir na senda fenomenológica cometendo o mesmo equívoco, pois, ao contrário, o filósofo desejou realizar uma análise da consciência em que a própria fosse o caminho efetivo para o conhecimento da realidade - tornando o ego, assim, o fundamento indubitável da própria realidade. Para chegar a esse ego, o filósofo partiu da Redução Fenomenológica - que nada mais é que a tentativa de alcançar verdades intelectivas seguras, tendo o ensaio "da dúvida universal" (HUSSERL, 2006, p. 78) para, como "expediente metódico", (HUSSERL, 2006, p. 78) estabelecer uma esfera ontológica indubitável.

É importante lembrar que essa é uma adoção de um tipo de ceticismo para combater o próprio ceticismo. Por isso, a entrada na epoché fenomenológica não significa uma 
UMA BREVE ANÁLISE SOBRE A RELAÇÃO CONSCIÊNCIA-MUNDO:...

negação do mundo, mas sim, uma colocação entre parênteses do mesmo - uma suspensão do juízo de verdade que se tem sobre ele. A primeira atitude tomada pelo método é estabelecer uma mudança na visão natural do mundo pela tentativa de desvelar o ego transcendental e sua evidência apodítica. O que Husserl chamou de "atitude natural" - ou "orientação natural” - pode ser explicada da seguinte forma: a atitude natural é aquela obtida vivendo no mundo - dando-se nele enquanto ser - e que considera a existência empírica do mesmo como verdade indubitável. Para o filósofo morávio, deve-se deixar a ingenuidade do ato de julgar a existência das coisas que compõem o mundo, e do próprio mundo, como um aspecto verdadeiro. É claro que a observação da existência do mundo ocorre por si, o mundo é um dado tão gritante que duvidar do ser que aí está parece um devaneio. Entretanto, seria o mundo em sua totalidade, e deve-se incluir teorias, objetos, pessoas, e todo o resto dos seus conjuntos, uma comprovação de teor apodítico?

Para a visão filosófica de Husserl, o mundo não é apenas o ser que denominamos de Terra, mas todo o horizonte de coisas que constituem sua totalidade. Por isso livros, uma cadeira, árvores, a teoria que explica o movimento dos objetos etc. são conteúdos componentes do ser do mundo. Porquanto, se se quer fundar uma ciência rigorosa é preciso também "retirar do terreno universal, do 
qual ele se alimenta, do terreno do mundo empírico, sua autoridade espontânea" (HUSSERL, 2001, p. 35). Ou seja, é necessária uma perspectiva contínua de que a visão natural que se tem sobre o mundo é invariavelmente passível de dúvida. O ser que existe, que aí está, deve ser colocado entre parênteses, voltando-se para ele apenas quando sua confirmação for evidentemente clara.

Empregar uma dúvida sobre o mundo estende o questionamento para os objetos pertencentes a ele. O que se pode compreender do mundo não é o seu teor de verdade indubitável - empiricamente dada - mas, ao contrário, a sua possibilidade invariável de ser duvidável. Por assim dizer, não podendo ter a crença no mundo como absolutamente evidente o valor de justificação da totalidade da experiência do próprio mundo acaba sendo perdido. Decerto, para sanar essa dúvida é necessário realizar uma suspensão dos juízos e encontrar um firmamento que seja uma evidência em si, assim como foi proposto por Descartes, e que servirá como base para a construção das demais crenças.

O domínio de existência natural, portanto, só tem uma autoridade de segunda categoria e pressupõe sempre o domínio transcendental. É por isso que o esforço fenomenológico fundamental, ou seja: $\varepsilon \pi o \chi \eta$ transcendental, na medida em que nos leva a esse 
UMA BREVE ANÁLISE SOBRE A RELAÇÃO CONSCIÊNCIA-MUNDO:...

domínio original chama-se redução fenomenológica transcendental. (HUSSERL, 2001, p. 39).

Após retirar do mundo seu valor de evidência primeira, algo, necessariamente, deverá ocupar seu lugar. A pergunta a ser feita após a redução é: se se pode duvidar do mundo, e de cada objeto, o que resta?

Como era imaginável, a resposta de Husserl foi simples e clara: o resíduo restante é o ego. Husserl afirmou, em síntese, que a consciência tem em si um "ser próprio, $o$ qual não pode ser atingido em sua essência própria absoluta pela exclusão fenomenológica" (HUSSERL, 2006, p. 84). Segue-se disso que o abrigo inabalável da ciência fenomenológica é o próprio ego. O que implica uma concepção de fenomenologia como ciência fundada na pura subjetividade - no absolutamente subjetivo. Invariavelmente, diria Husserl, todo pensamento tem como plano de fundo o próprio ego. Por isso os atos de percepção podem ser caracterizados como a ligação de um determinado eu com algo percebido - um objeto, uma sensação etc. A sensação de prazer, por exemplo, é prazerosa para um eu, assim como a de dor e a de alegria. Nenhuma exclusão de circuito (suspensão de juízo) pode suprimir a forma do cogito e eliminar o puro sujeito do ato de pensamento. É a esse ego, que está sempre e necessariamente lá e, por assim dizer, uma fôrma que dá 
forma aos conteúdos - anterior e ao mesmo tempo continuidade da expressão da consciência sobre si - que se denomina de ego transcendental. O ego transcendental, sendo consciência absoluta de si, mesmo com a total obliteração do mundo, permanece intocado. $\mathrm{O}$ ser imanente (o ego), assim sendo, é absoluto no sentido de que ele "não carece de coisa alguma para existir" (HUSSERL, 2006, p. 115). Por outro lado, em algo que pode ser denominado de idealismo transcendental fenomenológico, inverte-se a relação de conhecimento do mundo e o mundo passa a ser compreendido como completamente dependente da consciência - o mundo, posto pela intencionalidade, é um ser para a consciência.

A tese do mundo, que é uma tese 'contingente', contrapõe-se, portanto, a tese do meu eu puro e da vida do eu, que é uma tese 'necessária', pura e simplesmente indubitável (HUSSERL, 2006, p. 111).

A estrutura transcendental não é direcionada apenas para um mero eu sou e nem para um simples salvamento da possibilidade de conhecimento do mundo pela via da comprovação da existência de Deus, como, segundo Husserl, foi o que ocorreu na obra de Descartes. Os dados da experiência interna são estendíveis para uma possibilidade de compreensão fenomenológica - e a 
UMA BREVE ANÁLISE SOBRE A RELAÇÃO CONSCIÊNCIA-MUNDO:...

fenomenologia aparece como uma descrição do modo utilizado pela consciência para conhecer o mundo. Assim, a tarefa primordial da fenomenologia é o reconhecimento da estrutura do ego e de sua formulação transcendental como cognição das essências - da sua própria essência enquanto ego transcendental e das essências dos objetos percebidos.

O ego da redução aparece como uma espécie de espectador universal dos atos realizados pela consciência. Partindo dessa ligação complexa entre o ego transcendental e a consciência, no seu modo de percepção dos objetos empíricos, torna-se válido o conhecimento do mundo. Em linhas gerais, o ego engloba todos os aspectos da consciência e, subsequentemente, do próprio mundo. É por isso que:

[...]se depreende que o mundo é um problema egológico de caráter universal, o mundo vale, na orientação puramente imanente, para o conjunto da vida da consciência em sua duração imanente. (HUSSERL, 2001, p. 70).

A forma fenomenológica de observação do mundo é inseparável da subjetividade transcendental. A subjetividade transcendental confirma a experiência do mundo e demonstra qual a relação entre a realidade e os aspectos vividos pela consciência. $\mathrm{O}$ mundo, então, passa a ser um objeto dado pela unidade sintética da consciência. Seguindo 
a observação realizada por Ricoeur - citada no início deste texto - pode-se dizer que Husserl compreendeu o cogito como realmente absoluto, afinal, o filósofo morávio percebeu que existe apenas uma ordenação ontológica válida: aquela na qual o ego é efetivamente o primeiro, aquela na qual o mundo é dado por ele.

\section{NOTAS}

${ }^{1}$ Mestre em Filosofia pelo Programa de Pós-Graduação em Filosofia da Universidade Federal da Bahia (UFBA). Endereço eletrônico: estanislaufausto@outlook.com.

\section{REFERÊNCIAS BIBLIOGRÁFICAS}

DESCARTES, René. Discurso do Método. Tradução de Maria Ermantina Galvão. Revisão da tradução de Monica Stahel. São Paulo: Martins Fontes, 2001.

DESCARTES, René. Meditações Metafísicas. Tradução de Maria Ermantina Galvão. Tradução dos textos introdutórios de Homero Santiago. São Paulo: Editora WMF Martins Fontes, 4a. Ed. 2016. - (Clássicos WMF).

HUSSERL. Meditações Cartesianas. Trad. Frank de Oliveira. São Paulo: Madras Editora LTDA, 2001. 
UMA BREVE ANÁLISE SOBRE A RELAÇÃO CONSCIÊNCIA-MUNDO:...

HUSSERL. Meditações Cartesianas. Trad. Pedro M. S. Alves. Lisboa: Phainomenon, 2010.

HUSSERL. Ideias para uma fenomenologia pura e para uma filosofia fenomenológica. Trad. Márcio Suzuki. Aparecida: Idéias \& Letras, 2006. (Coleção Subjetividade Contemporânea).

LEBRUN, G. A filosofia e sua história. São Paulo: Ed. Cosac Naify, 2004.

MOURA, Carlos Alberto de. Crítica da razão na fenomenologia. - São Paulo: Nova Stella: Ed. Da USP, 1989.

RENAUT, Alain. L'Ère de l'Individu: Contribution à une histoire de la subjectivité. Paris: Éditeur. Gallimard, 1989

RICOEUR, Paul. O si-mesmo como outro. Tradução de Ivone C Benedetti. São Paulo: Ed. WMF Martins Fontes, 2001.

SARTRE, J.P. A Transcendência do Ego: Esboço de uma descrição fenomenológica. Introdução e notas de Sylvie Le Bom. Tradução de João Batista Kreuch. Petrópolis: Vozes, 2.ed. 2015. - (Coleção Textos Filosóficos). 